\title{
CONTINUOUS RADIAL FLOW CHROMATOGRAPHY OF PROTEINS
}

\author{
M. C. LAY*, C. J. FEE and J. E. SWAN \\ Department of Materials and Process Engineering, School of Science and Engineering, University of Waikato, Hamilton, New Zealand
}

\begin{abstract}
A continuous radial flow chromatography (CRFC) system consisting of an annular packed bed between two rotating concentric porous stainless steel cylinders was constructed and tested. The protein feed, wash buffer and elution buffer are applied simultaneously at different fixed angular positions at the periphery of the rotating bed and flow radially inwards. The target protein is bound in the feed zone and eluted in the elution zone while unbound protein flows through the feed zone. Continuity equations for fixed bed radial flow chromatography were extended to model the CRFC by including angular displacement terms, and solved using finite difference methods. Film diffusion at the resin particle boundary and pore diffusion within the resin particle was described by an overall mass transfer coefficient and a multicomponent Langmuir isotherm was used to describe protein absorption onto the resin particle. To verify the model, a solution containing $0.53 \mathrm{mg} \mathrm{ml}^{-1}$ lactoferrin and $1.6 \mathrm{mg} \mathrm{ml}^{-1}$ bovine serum albumin (BSA) was applied at $5 \mathrm{ml} \mathrm{min}^{-1}$ to a 220-ml CRFC system packed with DEAE Sepharose Fast Flow ion exchange resin, with abed speed of $0.02 \mathrm{rpm}$. The proteins were separated into lactoferrin of $68 \%$ purity ( $74 \%$ recovery) and BSA of $94 \%$ purity ( $85 \%$ recovery). Experimental data were used to find values for the parameters in the model proposed.
\end{abstract}

Keywords: annular; chromatography; continuous; radial; separation; protein.

\section{INTRODUCTION}

Radial flow chromatography offers several potential advantages over conventional axial flow column systems. It has a short bed depth and large area available for flow, allowing fast separations and low pressure drops (Saxena and Dunn, 1989; Levison, 2003), and has been used for a wide range of separations (e.g., Lapidus and Amundson, 1952; Jungbauer et al., 1988; Kim and Lee, 1996; Gustavsson and Larsson, 2001). Production scale protein separations are normally performed in batch mode requiring sequential steps: equilibration, loading, elution and regeneration. Unless the process is highly optimized, only a small section of the packed bed is used for the separation while the rest is a conduit, so the separation medium is not used efficiently (Barker and Ganetsos, 1988). Continuous processes increase efficiency by moving the chromatographic bed counter-, coor cross-current to fluid flow allowing greater use of the bed (Sussman and Rathore, 1975; Bridges and Barker, 1993). A widely applied continuous system is counter-current simulated moving bed chromatography (Thiele et al., 2001). A true moving bed system is annular bed chromatography, a cross-current axial flow apparatus, which has also been used for a wide range of applications (Fox et al., 1969;

*Correspondence to: Dr M. C. Lay, Department of Materials and Process Engineering, School of Science and Engineering, University of Waikato, Private Bag 3105, Hamilton, New Zealand.

E-mail: mclay@waikato.ac.nz
Scott et al., 1976; Bloomingburg and Carta, 1994; Bart et al., 1996; Giovannini and Freitag, 2002).

Radial flow chromatography may be made continuous by rotating the bed past fixed feed and exit points at the periphery and axis (Lay, 1998). Several models describing batch radial flow chromatography have been developed (Lapidus and Amundson, 1952; Gu et al., 1991; Tsaur and Shallcross, 1997). In this paper, the batch radial flow model is extended to continuous radial flow chromatography (CRFC) by including angular displacement to account for bed rotation. A prototype CRFC consisted of a rotating annulus $(8.6 \mathrm{~cm}$ i.d., $14.6 \mathrm{~cm}$ o.d. and $2 \mathrm{~cm}$ high) with equilibration, loading and elution buffers flowing radially inwards from different fixed positions around the periphery was used to verify the model. Bovine serum albumin (BSA) from a model mixture of lactoferrin and BSA was captured and carried around with the resin bed to the elution zone and eluted through an exit chamber at the axis.

\section{THEORY}

The continuity equation for solute $\mathrm{A}$ in a stationary (batch) radial flow column at position $r$ is

$$
\begin{aligned}
\frac{\partial C_{\mathrm{A}}}{\partial t} & +\left(\frac{1-\varepsilon_{\mathrm{R}}}{\varepsilon_{\mathrm{R}}}\right) \frac{\partial \bar{C}_{\mathrm{RA}}}{\partial t} \\
& =\frac{1}{r} \frac{\partial}{\partial r}\left(r D_{\mathrm{Ar}} \frac{\partial C_{\mathrm{A}}}{\partial r}\right)+\frac{D_{\mathrm{A} \theta}}{r^{2}} \frac{\partial^{2} C_{\mathrm{A}}}{\partial \theta^{2}}+\frac{Q}{\varepsilon_{\mathrm{R}} A_{\mathrm{r}}} \frac{\partial C_{\mathrm{A}}}{\partial r}
\end{aligned}
$$


where $C_{\mathrm{A}}$ is solute concentration in the resin interstices, $t$ is time, $\varepsilon_{\mathrm{R}}$ is external void fraction of the chromatographic media, $\bar{C}_{\mathrm{RA}}$ is the overall concentration of solute in the resin, $r$ is radius, $D_{\mathrm{Ar}}$ and $D_{\mathrm{A} \theta}$ are the radial and angular dispersion coefficients respectively, $\theta$ is angle in radians, $Q$ is flowrate in the radial direction, and $A_{\mathrm{r}}$ is radial column area perpendicular to flow direction $(\mathrm{Gu}$ et al., 1991; Tsaur and Shallcross, 1997). Assumptions implicit in this equation are that the annulus is uniformly packed and liquid and solid phases are incompressible, velocity is constant with height (axial) and angular position, concentration is constant with height so axial dispersion is negligible, and temperature is constant throughout. Relations for $D_{\mathrm{Ar}}$ and $D_{\mathrm{A} \theta}$ can be found in $\mathrm{Gu}$ et al. (1991) and Thiele et al. (2001).

When modelling rotating axial flow annular beds, continuity equations for axial flow columns are adapted using the relation from Wankat (1977),

$$
\Delta \theta=\Delta t \cdot w
$$

where $\Delta \theta$ is change in angle due to rotation and $w$ is rotational speed. A similar approach can be taken to model the CRFC. Substituting equation (2) into equation (1) and letting the limits approach zero gives

$$
\begin{aligned}
\frac{\partial C_{\mathrm{A}}}{\partial \theta} w & +\left(\frac{1-\varepsilon_{\mathrm{R}}}{\varepsilon_{\mathrm{R}}}\right) \frac{\partial \bar{C}_{\mathrm{RA}}}{\partial \theta} w \\
= & \frac{1}{r} \frac{\partial}{\partial r}\left(r D_{\mathrm{Ar}} \frac{\partial C_{\mathrm{A}}}{\partial r}\right)+\frac{D_{\mathrm{A} \theta}}{r^{2}} \frac{\partial^{2} C_{\mathrm{A}}}{\partial \theta^{2}}+\frac{Q}{\varepsilon_{\mathrm{R}} A_{\mathrm{r}}} \frac{\partial C_{\mathrm{A}}}{\partial r}
\end{aligned}
$$

Simulations of dispersive effects in axial columns show that dispersion due to convective mixing or eddy dispersion and molecular diffusion in the packed bed interstices is not significant in columns with short bed depths (Lay, 2005). The CRFC effective bed depth is only $3 \mathrm{~cm}$, so radial and angular dispersion can be neglected; therefore equation (3) becomes

$$
\frac{\partial C_{\mathrm{A}}}{\partial \theta} w+\left(\frac{1-\varepsilon_{\mathrm{R}}}{\varepsilon_{\mathrm{R}}}\right) \frac{\partial \bar{C}_{\mathrm{RA}}}{\partial \theta} w=\frac{Q}{\varepsilon_{\mathrm{R}} A_{\mathrm{r}}} \frac{\partial C_{\mathrm{A}}}{\partial r}
$$

$\bar{C}_{\mathrm{RA}}$ is a function of resin pore and bound resin concentrations, given by

$$
\frac{\partial \bar{C}_{\mathrm{RA}}}{\partial \theta} w=\frac{\partial C_{\mathrm{RPA}}}{\partial \theta} w \varepsilon_{\mathrm{p}}+\frac{\partial C_{\mathrm{RA}}}{\partial \theta} w
$$

where $C_{\mathrm{RPA}}$ is average resin pore concentration, $C_{\mathrm{RA}}$ is bound solute concentration and $\varepsilon_{\mathrm{p}}$ is resin pore fraction. $C_{\mathrm{RPA}}$ is given by

$$
\frac{\partial C_{\mathrm{RPA}}}{\partial \theta} w \varepsilon_{\mathrm{p}}=\frac{3 k_{\mathrm{fA}}\left(C_{\mathrm{A}}-C_{\mathrm{RPA}}\right)}{R_{\mathrm{p}}}-\frac{\partial C_{\mathrm{RA}}}{\partial \theta} w
$$

where $k_{\mathrm{fA}}$ is an overall mass transfer coefficient that includes both external film and pore mass transfer, calculated from Kaczmarski et al. (2001) or obtained by fitting the model to experimental data, and $R_{\mathrm{p}}$ is resin particle radius. A multicomponent Langmuir isotherm may be used to calculate $C_{\mathrm{RA}}$

$$
\begin{aligned}
\frac{\partial C_{\mathrm{RA}}}{\partial \theta} \frac{w}{\varepsilon_{\mathrm{p}}}= & k_{\mathrm{A} 1} C_{\mathrm{RPA}}\left(C_{\mathrm{RAmax}}-C_{\mathrm{RA}}\right) \\
& -k_{\mathrm{A} 2}\left(1+K_{\mathrm{d}} C_{\mathrm{RPB}}\right) C_{\mathrm{RA}}
\end{aligned}
$$

where $k_{\mathrm{A} 1}$ and $k_{\mathrm{A} 2}$ are forward and reverse equilibrium rates, $C_{\mathrm{RAmax}}$ is saturation capacity of the resin, $K_{\mathrm{d}}$ is a desorption parameter and $C_{\mathrm{RPB}}$ is resin pore $\mathrm{NaCl}$ concentration. Values for $k_{\mathrm{A} 1}, k_{\mathrm{A} 2}$ and $C_{\mathrm{RAmax}}$ can be obtained from fitting the model to experimental data. The equilibrium constant $K_{\mathrm{A}}$ is given by

$$
K_{\mathrm{A}}=\frac{k_{\mathrm{A} 1}}{k_{\mathrm{A} 2}}
$$

Substituting equations (5) and (6) into equation (4) gives the change in interstitial concentration with angle

$$
\frac{\partial C_{\mathrm{A}}}{\partial \theta} w=\frac{Q}{\varepsilon_{\mathrm{R}} A_{\mathrm{r}}} \frac{\partial C_{\mathrm{A}}}{\partial r}-\frac{3 k_{\mathrm{fA}}\left(C_{\mathrm{A}}-C_{\mathrm{RPA}}\right)}{R_{\mathrm{p}}} \frac{\left(1-\varepsilon_{\mathrm{R}}\right)}{\varepsilon_{\mathrm{R}}}
$$

Solute concentration within the annular walls can be calculated by removing the resin concentration term from equation (4) giving

$$
\frac{\partial C_{\mathrm{A}}}{\partial \theta} w=\frac{Q}{\varepsilon_{\mathrm{R}} A_{\mathrm{r}}} \frac{\partial C_{\mathrm{A}}}{\partial r}
$$

Step changes in solute input concentrations with angular position around the outer annulus wall periphery depend on position and width of the solute feed sections. Input concentrations are assumed to be constant with time and boundary conditions used in the model are in Table 1. Solutions exit the annulus via eight sections. Each section is assumed to be well mixed and the solute concentration in each is averaged over the entire section width.

The model was solved using an explicit finite difference method and simulations were run using Matlab ${ }^{\mathrm{TM}}$ (Lay, 2005). It was assumed that lactoferrin and BSA did not compete for DEAE sepharose resin binding sites as lactoferrin should not bind at $\mathrm{pH} 7$ (Table 2). Chloride ions were assumed to compete with BSA for resin binding sites but BSA was not expected to affect the $\mathrm{NaCl}$ concentration profile because the $\mathrm{NaCl}$ molar concentration was many times greater than BSA. Therefore, $K_{\mathrm{d}}$ for both the chloride ions and lactoferrin should be zero.

Table 1. Boundary conditions at the outer annulus wall periphery.

\begin{tabular}{llcc}
\hline $\begin{array}{l}\text { Feed } \\
\text { chamber } \\
\text { sections }\end{array}$ & Solution & $\begin{array}{c}\text { Section } \\
\text { boundaries } \\
\text { (degrees) }\end{array}$ & $\begin{array}{c}\text { Input } \\
\text { concentrations } \\
\left(\mathrm{mg} \mathrm{ml}^{-1}\right)\end{array}$ \\
\hline 1 & Protein feed & $0<\theta \leq 45$ & $C_{\mathrm{A}}=C_{\text {feed }}, C_{\mathrm{B}}=0$ \\
$2-4$ & Wash & $45<\theta \leq 180$ & $C_{\mathrm{A}}=0, C_{\mathrm{B}}=0$ \\
5 & Elution & $180<\theta \leq 225$ & $C_{\mathrm{A}}=0, C_{\mathrm{B}}=C_{\text {elution }}$ \\
$6-8$ & Equilibration & $225<\theta \leq 360$ & $C_{\mathrm{A}}=0, C_{\mathrm{B}}=0$ \\
\hline
\end{tabular}


Table 2. Properties of BSA and lactoferrin.

\begin{tabular}{lccc}
\hline Protein & MW $(\mathrm{kDa})$ & $\mathrm{pI}$ & Reference \\
\hline BSA & 67 & $4.98-5.18$ & Whitley et al., 1989 \\
Lactoferrin & $77-80$ & $8-9$ & Moore et al., 1997; \\
& & & Brock, 2002 \\
\hline
\end{tabular}

\section{EXPERIMENTAL METHOD}

Details of the CRFC system design can be found in Lay (2005). The CRFC column was pump packed with $500 \mathrm{ml}$ of DEAE Sepharose Fast Flow anion exchanger (Amersham Biosciences, Uppsala, Sweden) suspended in $3 \mathrm{~L}$ of $1 \mathrm{M} \mathrm{NaCl}$ solution. All ports at the periphery were connected to a flow manifold, which was attached to an AKTAexplorer100 liquid chromatography system (Amersham Biosciences, Uppsala, Sweden). The CRFC was equilibrated with $2 \mathrm{~L}$ of $0.02 \mathrm{M} \mathrm{pH} 7$ Tris(hydroxymethyl)methylamine (BDH Laboratory Supplies or Appli-

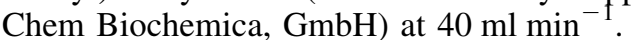

Three sets of experiments were performed. In the first, feed containing $1.6 \mathrm{mg} \mathrm{ml}^{-1}$ Fraction $\mathrm{V}$ bovine serum albumin (BSA) (low endotoxin, Life Technologies GibcoBRL) and $0.53 \mathrm{mg} \mathrm{ml}^{-1}$ bovine lactoferrin (Tatua Co-operative Dairy Company Ltd, Morrinsville, New Zealand) in equilibration buffer was pumped to section 1 of the CRFC (Figure 1) at $5 \mathrm{ml} \mathrm{min}^{-1}$ using an Amersham Pharmacia P6000 syringe pump. Elution buffer containing $1 \mathrm{M} \mathrm{NaCl}$ in equilibration buffer was supplied to section 5 of the CRFC using an Amersham Pharmacia P-500 syringe pump. Wash zones between the feed and elution zones were created by pumping equilibration buffer at a total flowrate of $30 \mathrm{ml} \mathrm{min}{ }^{-1}$ to the remaining six inputs. The CRFC was operated continuously at $0.02 \mathrm{rpm}$ for three hours to ensure steady state, and then samples were collected from each effluent stream over the next $3 \mathrm{~h}$. The CRFC was then configured for batch operation by stopping the bed rotation. The resin was regenerated with 21 of elution buffer and 1.51 of $1 \mathrm{M} \mathrm{NaOH}$, and flushed with 41 of distilled water. All

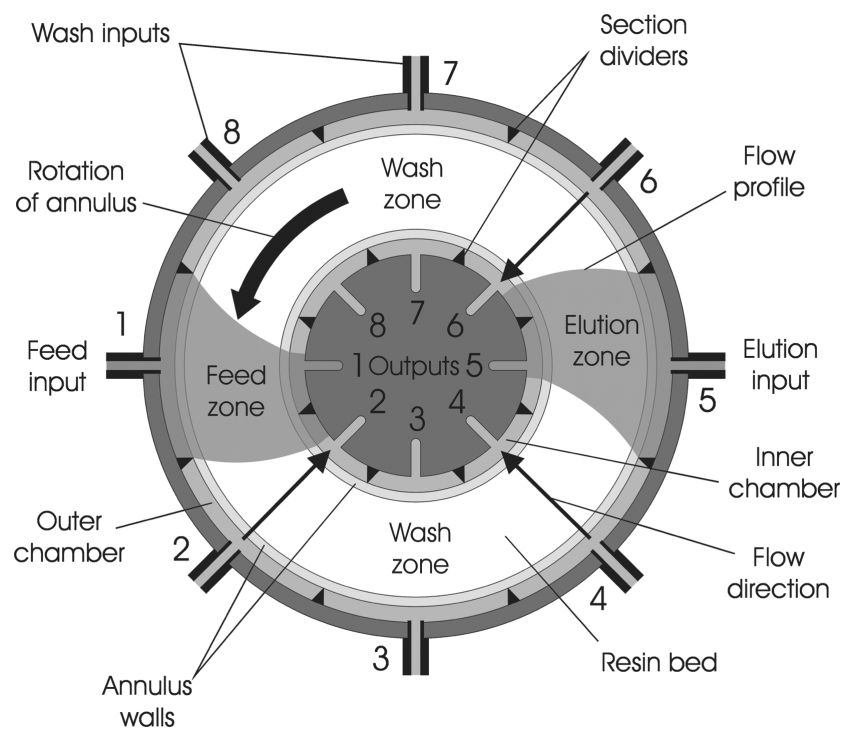

Figure 1. Flow profiles through the CRFC. effluent was collected and analysed for total protein by absorbance at $280 \mathrm{~nm}$ (Ultraspec $2000 \mathrm{UV} /$ visible spectrophotometer) and conductivity (Cyberscan Con 100 conductivity probe). Lactoferrin in effluent samples was determined by surface plasmon resonance (Biacore 3000, Uppsala, Sweden) (Indyk and Filonzi, 2004). The BSA content was determined by absorbance at $280 \mathrm{~nm}$ after allowing for lactoferrin content. Mass balances of BSA, lactoferrin and $\mathrm{NaCl}$ were calculated.

In the second and third sets of trials, the feed contained $1.6 \mathrm{mg} \mathrm{ml}^{-1} \mathrm{BSA}$ only. The CRFC was operated at 0.080 , 0.032 and $0.020 \mathrm{rpm}$ in the second set and in the third set, the outer section dividers were set 15 and 30 degrees anticlockwise from the inner section dividers and the CRFC was operated at $0.08 \mathrm{rpm}$.

\section{RESULTS AND DISCUSSION}

Elution profiles (Figure 2) show BSA and lactoferrin can be separated using the CRFC. Mass balances showed that $85 \%$ of the BSA was recovered in the BSA collection zone (sections $4-7$ ) at $94 \%$ purity and $74 \%$ of the lactoferrin was recovered in the lactoferrin collection zone (sections 1-3 and 8 ) at $68 \%$ purity (Table 3 ). The separation factor for BSA, given by

$$
\alpha_{\mathrm{BSA} / \mathrm{Lf}}=\frac{C_{\mathrm{BSA}(\text { feed })} / C_{\mathrm{L}(\text { feed })}}{C_{\mathrm{BSA}(\text { eluent })} / C_{\mathrm{Lf}(\text { eluent })}}
$$

was 4.79. Mass recoveries were $96 \%$ for BSA and $92 \%$ for lactoferrin, indicating that some protein was retained by the media in the CRFC. Total mass balances for both proteins after cleaning and regenerating the CRFC closed within $5 \%$. The slight increase in lactoferrin concentration in the elution zone (section 5 in Figure 2) indicates nonspecific binding to the resin. Lactoferrin was not expected to bind to DEAE Sepharose FF at pH 7, so this non-specific binding may be due to interaction with resin-bound BSA.

The eluate from the current prototype was dilute so further downstream processing such concentration by ultrafiltration would be needed. Alternatively, the CRFC could be optimized to produce a more concentrated product by

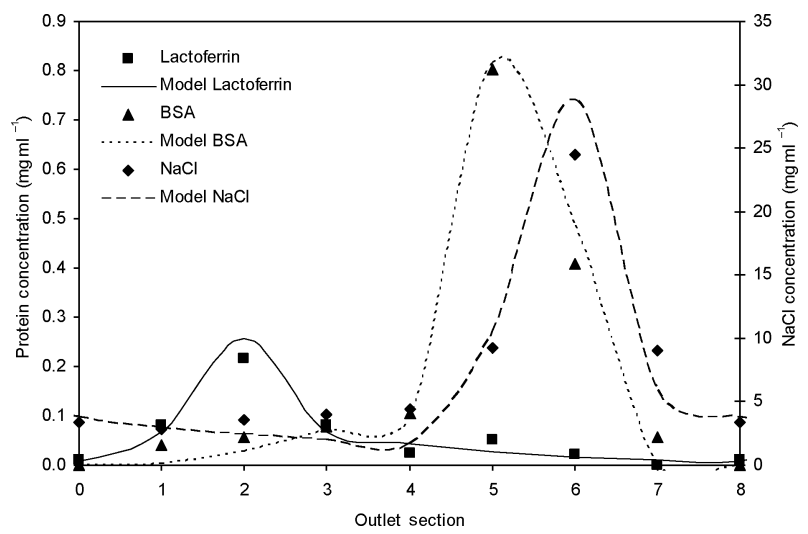

Figure 2. Elution profiles of BSA, lactoferrin and $\mathrm{NaCl}$ from the CRFC. Feed was $1.6 \mathrm{mg} \mathrm{mL}^{-1} \mathrm{BSA}$ and $0.53 \mathrm{mg} \mathrm{mL}^{-1}$ lactoferrin, total flow $40 \mathrm{~mL} \mathrm{~min}^{-1}$, feed flow $5 \mathrm{~mL} \mathrm{~min}^{-1}$ to section 1 , elution flow $5 \mathrm{~mL} \mathrm{~min}^{-1}$ to section 5 , rotation speed $0.02 \mathrm{rpm}$. 
Table 3. Yield and purity of BSA and lactoferrin recovered during sample collection.

\begin{tabular}{lcc}
\hline & Lactoferrin & BSA \\
\hline Yields (\%) & 74 & \\
LF zone (sections 1-3, 8) & 18 & 11 \\
BSA zone (sections 4-7) & 92 & 85 \\
Total mass recovery (\%) & & 96 \\
Purity of fractions recovered (\%) & 68 & 32 \\
LF zone (sections 1-3, 8) & 6 & 94 \\
BSA zone (sections 4-7) & & \\
\hline
\end{tabular}

increasing the loading zone size relative to the elution zone and increasing the elution buffer strength, slowing rotation speed to narrow the elution peak and increase loading time, and adjusting the exit section positions so most of the captured protein elutes into one section. If a one degree segment ( $\sim 0.56 \mathrm{ml}$ bed) of the resin bed is followed as it revolves about the CRFC axis, analysis indicates only $1 \mathrm{mg}$ of BSA is loaded onto the resin each cycle $(6 \mathrm{~min}$ in the loading zone at $\sim 0.02 \mathrm{rpm}$ and $0.11 \mathrm{ml} \mathrm{min}^{-1}$ flow through the segment). Previous studies (Lay, 2005) showed BSA breakthrough in a 1-ml DEAE Sepharose FF axial flow column at similar interstitial velocities occurs after loading $37.5 \mathrm{mg}$ protein at $1.5 \mathrm{mg} \mathrm{ml}^{-1}$ and has completely eluted after applying $3 \mathrm{CV}$ of elution buffer. To load the resin to similar capacities in the CRFC, the loading zone should be approximately 264 degrees, and the elution and two wash zones 32 degrees each, and the rotation speed set at $3 \mathrm{~h}$ per revolution. Assuming no loss of protein in the loading and wash zones, the eluate would be approximately eight times the concentration of the feed stock. Optimization studies were not performed however as we were wanting to demonstrate proof of the CRFC concept.

The CRFC resolution is limited by the number of sections in the exit chamber, therefore the CRFC is only suitable for a first or second stage low resolution step elution product capture. Resolution can be increased by increasing the number of sections in the exit chamber. However, this involves increasing the inner annulus and CRFC exit chamber diameters to accommodate more sections and would make CRFC construction and operation more complex so it was not explored.

The CRFC operating pressure steadily increased from 165 to $228 \mathrm{kPa}$ over $6 \mathrm{~h}$ due to protein resin fouling, which was removed by leaving regeneration buffer in the column overnight. The fouling probably occurs because the elution zone is not large enough to allow sufficient time for the protein to diffuse from the resin at the flowrate and rotation speeds used. The resin spent 6 min within the elution zone each cycle at the rotation speed used in the experiment. $\mathrm{NaCl}$ concentration in the elution zone reached $25 \mathrm{mg} \mathrm{ml}^{-1}$ (Figure 2), which may increase BSA mobility in the resin pores allowing the BSA to diffuse deeper into the resin. Commercially available BSA contains a small fraction of dimers, which have been shown to bind more strongly to anion exchangers than monomers (Hunter and Carta, 2001). Therefore, elution buffer concentration may be too low to elute the dimer. Fouling may be solved by increasing the size of the elution zone, increasing elution buffer strength, or lowering annulus rotation speed, but these were not investigated.
An excellent fit with experimental data was achieved using the model parameters in Table 4. Adsorption favoured BSA, which had a $K_{\mathrm{A}}=47 \mathrm{ml} \mathrm{mg}^{-1}$ compared to $K_{\mathrm{A}}=0.6 \mathrm{ml} \mathrm{mg}^{-1}$ for lactoferrin. The BSA binding capacity of $72 \mathrm{mg} \mathrm{ml}^{-1}$ was slightly lower than reported values of $85 \mathrm{mg} \mathrm{ml}^{-1}$ for DEAE Sepharose FF at $\mathrm{pH}$ 8.1-8.5 (James and Do, 1991; Liu et al., 2001). The lower value was probably due to the lower $\mathrm{pH}$ used $(\mathrm{pH} 7)$. The separation factor value calculated by the model for BSA was 4.73 which is consistent with the experimentally obtained value of 4.79 .

A constant value for $k_{\mathrm{fA}}$ was used for model simplicity. However the value depends on interstitial velocity, which increases twofold from the CRFC annulus periphery to the inner wall. Axial column experiments to determine BSA breakthrough behaviour in a 1-ml DEAE Sepharose FF column at different interstitial velocities showed that changes in $k_{\mathrm{fA}}$ with radial position were small for the CRFC (Lay, 2005). However, a velocity dependency term should be incorporated to increase model accuracy where there are large changes in interstitial velocity (e.g., in a i.d. $2 \mathrm{~cm}$ and o.d. $30 \mathrm{~cm}$ radial column where solution velocity increases 15 fold).

Unexpectedly, $\mathrm{NaCl}$ tailing was observed (Figure 2), which could only be modelled using an unrealistically high $C_{\mathrm{RBmax}}$ of $56 \mathrm{mg} \mathrm{ml}^{-1}$. The model failed to predict $\mathrm{NaCl}$ tailing when the actual resin capacity of 3.4-5.7 $\mathrm{mg} \mathrm{Cl}^{-} \mathrm{ml}^{-1}$ (Amersham Biosciences) was used. The experimental result may be due to an equilibrium interaction of $\mathrm{Na}^{+}$and $\mathrm{Cl}^{-}$ions with protein accumulated within the resin, which would cause the ions to take longer than expected to diffuse from the resin.

As rotation speed was increased, the BSA (Figure 3) elution peaks broadened. The increase in angular displacement due to higher rotation speed caused most of the BSA to elute in section 6 at $0.032 \mathrm{rpm}$ and over sections $6-8$ and 1 at $0.08 \mathrm{rpm}$. Likewise, moving outer section dividers 15 and 30 degrees anticlockwise relative to the inner dividers caused most of the BSA to elute into section 6 (Figure 4). Similar effects were observed with $\mathrm{NaCl}$ elution profiles (omitted from Figures 3 and 4 for clarity, see Lay, 2005). Parameters for BSA, obtained from fitting the model to data in the second and third sets of experiments, were identical to those obtained in the first set and similar to those obtained from BSA breakthrough experiments using an axial flow column (data not shown) (Lay, 2005). Therefore, the model can predict elution profiles for a range of CRFC rotation speeds and divider angles. Obtaining similar model parameters indicate that axial, angular and radial dispersion effects in the CRFC were negligible, so adsorption and

Table 4. Parameters for simulating BSA, lactoferrin and $\mathrm{NaCl}$ concentration profiles from the CRFC for conditions given in Figure 2 and $\varepsilon_{\mathrm{R}}=0.31$ and $\varepsilon_{\mathrm{p}}=0.72$.

\begin{tabular}{llll}
\hline Parameters & BSA & Lactoferrin & $\mathrm{NaCl}$ \\
\hline$k_{\mathrm{fA}}\left(\mathrm{cm} \mathrm{s}^{-1}\right)$ & 0.0001 & 0.0001 & 0.00005 \\
$K_{\mathrm{A}}\left(\mathrm{mL} \mathrm{mg}^{-1}\right)$ & 47 & 0.6 & 0.15 \\
$k_{\mathrm{A} 1}\left(\mathrm{~mL} \mathrm{mg}^{-1} \mathrm{~s}\right)$ & 0.003 & 0.0015 & 0.00015 \\
$k_{\mathrm{A} 2}\left(1 \mathrm{~s} \mathrm{~s}^{-1}\right)$ & 0.00006 & 0.0025 & 0.001 \\
$C_{\mathrm{RAmax}}\left(\mathrm{mg} \mathrm{mL}^{-1}\right)$ & 72 & 3 & 56 \\
$K_{\mathrm{d}}\left(\mathrm{mL} \mathrm{mg}^{-1}\right)$ & 400 & 0 & 0 \\
\hline
\end{tabular}




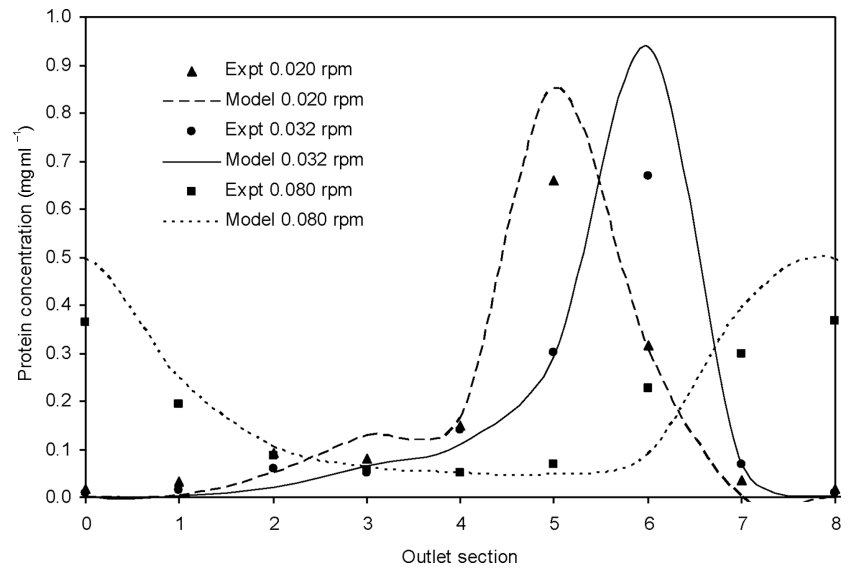

Figure 3. Effect of rotation speed on BSA elution profiles. Feed was $1.5 \mathrm{mg} \mathrm{mL}^{-1} \mathrm{BSA}$, total flow $40 \mathrm{~mL} \mathrm{~min}^{-1}$, feed flow $5 \mathrm{~mL} \mathrm{~min}^{-1}$ to

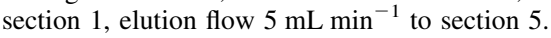

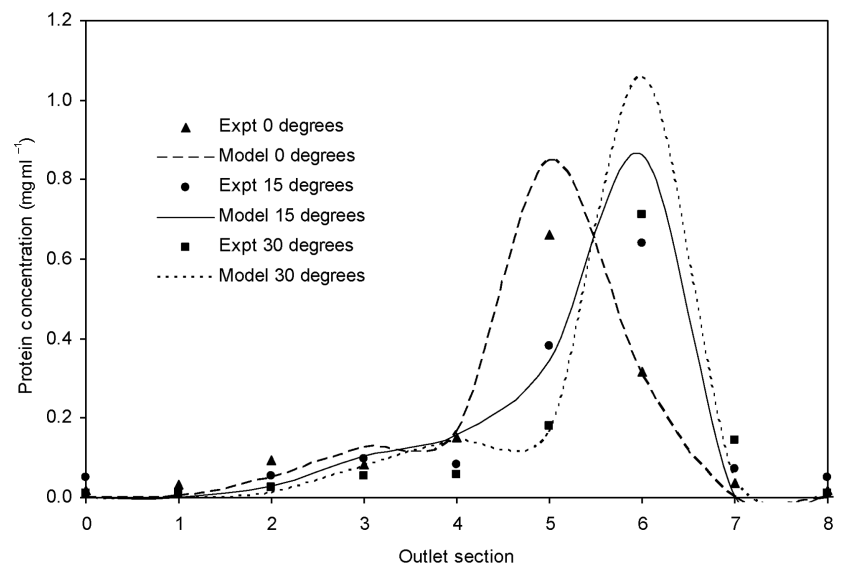

Figure 4. Effect of outer divider angles on BSA elution profiles. Feed was $1.5 \mathrm{mg} \mathrm{mL}^{-1} \mathrm{BSA}$, total flow $40 \mathrm{~mL} \mathrm{~min}^{-1}$, feed flow of $5 \mathrm{~mL} \mathrm{~min}^{-1}$ section 1 , elution flow $5 \mathrm{~mL} \mathrm{~min}^{-1}$ to section 5 , rotation speed $0.02 \mathrm{rpm}$.

mass transfer parameters obtained from axial column experiments can be used to predict CRFC performance. Any differences in parameter values when fitting CRFC and axial column data to the model may be due to minor irregularities in CRFC bed packing or wall effects giving slight non-uniform flow in axial, radial and angular directions. These differences did not significantly change the simulated BSA elution profile (Lay, 2005). Dividing the exit chamber into only eight sections may dampen any effect that could occur.

Future trials with the CRFC will investigate the effect of feed flowrate, feed concentration and different sized proteins on elution profiles.

\section{CONCLUSIONS}

The CRFC was used to separate BSA from lactoferrin. A separation factor for BSA of 4.79 was achieved, showing the CRFC has excellent potential for first or second stage low-resolution product capture. The CRFC currently produces a dilute purified product, but in theory the product concentration could potentially be raised to eight times the BSA feed concentration by optimizing operational parameters. The separation could be modeled by adding angular momentum terms to conventional batch radial flow continuity equations, neglecting dispersion, using an overall mass transfer coefficient that includes film and pore diffusion, and a multicomponent Langmuir isotherm. The mathematical model developed will allow the effects of rotation speed and loading and elution zone size in optimizing the CRFC to be explored.

\section{NOMENCLATURE}

$A_{\mathrm{r}}$
$C_{\mathrm{A}}$
$C_{\mathrm{B}}$
$C_{\mathrm{BSA}}$
$C_{\text {elution }}$
$C_{\text {feed }}$
$C_{\mathrm{Lf}}$
$C_{\mathrm{RA}}$
$\bar{C}_{\mathrm{RA}}$
$C_{\mathrm{RAmax}}$
$C_{\mathrm{RBmax}}$
$C_{\mathrm{RPA}}$
$C_{\mathrm{RPB}}$
$D_{\mathrm{Ar}}$
$D_{\mathrm{A} \theta}$
$k_{\mathrm{fA}}$
$k_{\mathrm{A} 1}$
$k_{\mathrm{A} 2}$
$K_{\mathrm{A}}$
$K_{\mathrm{d}}$
$Q$
$r$
$R_{\mathrm{p}}$
$t$
$w$
$\theta$
$\varepsilon_{\mathrm{p}}$
$\alpha_{\mathrm{BSA}}$
$\varepsilon_{\mathrm{L}}$

area in radial direction, $\mathrm{cm}^{2}$ solute A concentration, $\mathrm{mg} \mathrm{ml}^{-1}$ solute B concentration, $\mathrm{mg} \mathrm{ml}^{-1}$ BSA concentration, $\mathrm{mg} \mathrm{ml}^{-1}$ elution buffer concentration, $\mathrm{mg} \mathrm{ml}^{-1}$ feed concentration, $\mathrm{mg} \mathrm{ml}^{-1}$ lactoferrin concentration, $\mathrm{mg} \mathrm{ml}^{-1}$ bound resin concentration, $\mathrm{mg} \mathrm{ml}^{-1}$ overall resin concentration, $\mathrm{mg} \mathrm{ml}^{-1}$ solute A bound resin concentration at saturation, $\mathrm{mg} \mathrm{ml}^{-1}$ solute $\mathrm{B}$ bound resin concentration at saturation, $\mathrm{mg} \mathrm{ml}^{-1}$ resin pore concentration, $\mathrm{mg} \mathrm{ml}^{-1}$

$\mathrm{NaCl}$ resin pore concentration, $\mathrm{mg} \mathrm{ml}^{-1}$ dispersion in radial direction, $\mathrm{cm}^{2} \mathrm{~s}^{-1}$ dispersion in angular direction, $\mathrm{cm}^{2} \mathrm{~s}^{-1}$ overall mass transfer coefficient, $\mathrm{cm} \mathrm{s}^{-1}$ uptake rate by packed bed, $\mathrm{ml} \mathrm{mg}^{-1} \mathrm{~s}^{-1}$ desorption rate, $\mathrm{s}^{-1}$

equilibrium constant, $\mathrm{ml} \mathrm{mg}^{-1}$ desorption parameter, $\mathrm{ml} \mathrm{mg}^{-1}$ flow-rate, $\mathrm{ml} \mathrm{s}^{-1}$

radius, $\mathrm{cm}$

resin particle radius, $\mathrm{cm}$

time, $\mathrm{s}$

rotational speed, radians per second

separation factor for BSA/lactoferrin

external pore fraction of resin internal void fraction of resin angle, radians

\section{REFERENCES}

Barker, P.E. and Ganetsos, G., 1988, Chemical and biochemical separations using preparative and large-scale batch and continuous chromatography, Separation and Purification Methods, 17(1): 1-65.

Bart, H.J., Messenbock, R.C., Byers, C.H., Prior, A. and Wolfgang, J., 1996, Continuous chromatographic separation of fructose, mannitol and sorbitol, Chemical Engineering and Processing, 35(6): 459-471.

Bloomingburg, G.F. and Carta, G., 1994, Separation of protein mixtures by continuous annular chromatography with step elution, Chemical Engineering Journal, 55: B19-B27.

Bridges, S. and Barker, P.E., 1993, Continuous cross-current chromatographic refiners, in Ganetsos, P. and Barker, P.E. (eds). Preparative and Production Scale Chromatography, Vol. 63, pp. 113-126 (Marcel Dekker, New York).

Brock, J.H., 2002, The physiology of lactoferrin, Biochemistry and Cell Biology, 80: 1-6.

Fox, J.B.J., Calhoun, R.C. and Eglington, W.J., 1969, Continuous chromatography apparatus I. Construction, Journal of Chromatography, 43: $48-54$.

Giovannini, R. and Freitag, R., 2002, Continuous isolation of plasmid DNA by annular chromatography, Biotechnology and Bioengineering, 77(4): 445-454.

Gu, T.Y., Tsai, G.J. and Tsao, G.T., 1991, A theoretical study of multicomponent radial flow chromatography, Chem Eng Sci, 46(5-6): $1279-1288$.

Gustavsson, P.E. and Larsson, P.O., 2001, Continuous superporous agarose beds in radial flow columns, Journal of Chromatography A, 925(1-2): $69-78$. 
Hunter, A.K. and Carta, G., 2001, Effects of bovine serum albumin heterogeneity on frontal analysis with anion-exchange media, Journal of Chromatography A, 937(1-2): 13-19.

Indyk, H.E. and Filonzi, E.L., 2005, Determination of lactoferrin in bovine milk, colostrum and infant formulas by optical biosensor analysis, International Dairy Journal, 15(5): 429-438.

James, E.A. and Do, D.D., 1991, Equilibria of biomolecules on ionexchange adsorbents, Journal of Chromatography, 542: 19-28.

Jungbauer, A., Pettauer, D., Buchacher, A., Wenisch, E., Unterluggauer, F., Uhl, K. and Steindl, F., 1988, Scaleup of monoclonal-antibody purification using radial streaming ion-exchange chromatography, Biotechnology and Bioengineering, 32(3): 326-333.

Kaczmarski, K., Antos, D., Sajonz, H., Sajonz, P. and Guiochon, G., 2001, Comparative modeling of breakthrough curves of bovine serum albumin in anion-exchange chromatography, Journal of Chromatography A, 925 : $1-17$.

Kim, Y.H. and Lee, E.K., 1996, Comparison of axial and radial flow chromatography on protein separation speed and resolution, Korean Journal of Chemical Engineering, 13(5): 466-472.

Lapidus, L. and Amundson, N.R., 1952, The rate-determining steps in radial adsorption analysis, Journal of Physical Chemistry, 56: $373-383$.

Lay, M.C., 1998, Continuous radial flow chromatography, MSc thesis, University of Waikato, Hamilton, New Zealand.

Lay, M.C., 2005, Continuous radial flow chromatography, PhD thesis, University of Waikato, Hamilton, New Zealand.

Levison, P.R., 2003, Large-scale ion-exchange column chromatography of proteins: Comparison of different formats, Journal of Chromatography B, 790(1-2): 17-33.
Liu, Z., Yin, G., Feng, S., Wang, D., Ding, F. and Yuan, N., 2001, Oscillatory electroosmosis-enhanced intra/inter-particle liquid transport and its primary applications in the preparative electrochromatography of proteins, Journal of Chromatography A, 921(1): 93-98.

Moore, S.A., Anderson, B.F., Groom, C.R., Haridas, M. and Baker, E.N., 1997, Three-dimensional structure of diferric bovine lactoferrin at $2.8 \mathrm{~A}$ resolution, Journal of Molecular Biology, 274(Nov): 222-236.

Saxena, V. and Dunn, M., 1989, Solving scale-up: Radial flow chromatography. Bio/Technology, 7(3): 250.

Scott, C.D., Spence, R.D. and Sisson, W.G., 1976, Pressurized, annular chromatograph for continuous separations, Journal of Chromatography, 126: $381-400$.

Sussman, M.V. and Rathore, R.N.S., 1975, Continuous modes of chromatography, Chromatographia, 8: 55.

Thiele, A., Falk, T., Tobiska, L. and Seidel-Morgenstern, A., 2001, Prediction of elution profiles in annular chromatography, Computers \& Chemical Engineering, 25(7-8): 1089-1101.

Tsaur, Y. and Shallcross, D.C., 1997, Modeling of ion exchange performance in a fixed radial flow annular bed, Industrial Engineering and Chemistry Research, 36: 2359-2367.

Wankat, P.C., 1977, The relationship between one-dimensional and twodimensional separation processes, AIChE J, 23(6): 859-867.

Whitley, R.D., Wachter, R., Liu, F. and Wang, N.H.L., 1989, Ionexchange equilibria of lysozyme, myoglobin and bovine serum albumin. Effective valence and exchanger capacity, Journal of Chromatography, 465: $137-156$.

The manuscript was received 18 July 2005 and accepted for publication after revision 16 January 2006. 